07

\title{
Роль зарядового состояния \\ поверхностных атомов металлической подложки в допировании квазисвободного графена
}

\author{
(C) С.Ю. Давыдов ${ }^{1}$, А.А. Лебедев ${ }^{1,2}$, Ю.В. Любимова ${ }^{3}$ \\ ${ }^{1}$ Физико-технический институт им. А.Ф. Иоффре РАН, Санкт-Петербург, \\ Россия \\ ${ }^{2}$ Санкт-Петербургский государственный электротехнический университет \\ „ЛЭТИ“, Санкт-Петербург, Россия \\ ${ }^{3}$ Санкт-Петербургский национальный исследовательский университет \\ информационных технологий, механики и оптики, Санкт-Петербург, \\ Россия \\ E-mail: Sergei_Davydov@mail.ru
}

Поступило в Редакцию 19 апреля 2018 г.

Для оценки влияния металлической подложки на электронное состояние квазисвободного графена предложена простая модель, учитывающая наличие двойного электрического слоя на поверхности металла. Возникающее при этом электростатическое поле сдвигает точку Дирака графена, что приводит к его допированию. Получено аналитическое выражение для заряда атомов графена. Численные оценки сделаны для граней (111) $\mathrm{Cu}, \mathrm{Ag}, \mathrm{Au}$ и Pt. Обсуждается согласие полученных оценок с имеющимися результатами численных расчетов.

DOI: 10.21883/PJTF.2018.23.47015.17347

Влияние электростатических полей субстратов $4 H$ - и $6 H$-SiC на допирование квазисвободного однолистного графена впервые было рассмотрено в работах [1-5], где в качестве источника поля выступала спонтанная поляризация гексагональных политипов карбида кремния. В [6] изучалось влияние интеркалированного водорода на электронное состояние квазисвободного графена на $\mathrm{SiC}$-подложке и было показано, что определяющую роль играет уже не спонтанная поляризация, а электростатическое поле дипольной решетки, образованной заряженными адатомами водорода и их изображениями в подложке. В настоящей 
работе рассматривается квазисвободный графен, сформированный на поверхности металлической подложки.

Хорошо известно, что атомы поверхностного слоя металлической подложки имеют заметный положительный заряд $Z_{s}$ [7]. Такой слой можно рассматривать как монослой заряженных адатомов. Электростатическое поле $F_{s}$, создаваемое этим слоем, вызывает смещение всех энергетических уровней графена вниз по оси энергии на величину $u_{g}=-e F_{s}(l) l$, где $l-$ расстояние между подложкой и параллельно расположенным листом графена, $e-$ заряд позитрона. В частности, точка Дирака изолированного графена $\varepsilon_{\mathrm{D}}$ сдвигается в положение $\varepsilon_{\mathrm{D}}^{\prime}=\varepsilon_{\mathrm{D}}+u_{g}$. Ясно, что такой сдвиг приводит к переходу дополнительного числа электронов на графен.

В теоретических работах $[8,9]$ путем численных расчетов в рамках DFT (density functional theory) было показано, что даже при слабой связи графенового листа с гранями (111) таких $d$-металлов, как $\mathrm{Cu}$, $\mathrm{Ag}, \mathrm{Au}$ и $\mathrm{Pt}$, электронное состояние графена сильно изменяется. Здесь для объяснения подобного способа допирования графена предложена простая модель, позволяющая получить результаты в аналитическом виде.

Начнем с определения затравочного значения заряда $Z_{s 0}$ поверхностных атомов (адатомов) металла, испытывающих взаимное дипольдипольное отталкивание, но не взаимодействующих с графеном. Как известно [10-12], в рамках гамильтониана Андерсона и модели дипольного взаимодействия Муската-Ньюнса значение $Z_{s 0}$ определяется самосогласованным уравнением

$$
Z_{s 0}=\frac{1}{2}+\frac{1}{\pi} \operatorname{arctg} \frac{\varepsilon_{m}-\varepsilon_{\mathrm{F}}-\xi_{m} Z_{s 0}}{\Gamma_{m}} .
$$

Здесь $\varepsilon_{m}$ - энергия квазиуровня поверхностного атома металла с полушириной $\Gamma_{m} ; \varepsilon_{\mathrm{F}}-$ энергия Ферми металла; $\xi_{m}=2 e^{2} A / d_{m}-$ константа диполь-дипольного отталкивания металлических адатомов; учтено, что площадь, приходящаяся на один атом поверхности (111) ГЦК-металла, равна $S_{m}=(8 \sqrt{3} / 15) d_{m}^{2} \sim d_{m}^{2} ; d_{m}$ - расстояние между ближайшими соседями в металле; $A \sim 10-$ коэффициент, слабо зависящий от структуры адсорбированного слоя. Здесь и далее температура считается равной нулю.

Положим, как обычно $[10], \varepsilon_{m}-\varepsilon_{\mathrm{F}}=\phi_{m}-I+e^{2} / 4 d_{m}$, где $\phi_{m}-$ работа выхода металла, $I$ - энергия ионизации атома металла.

Письма в ЖТФ, 2018, том 44, вып. 23 
В соответствии с моделью Андерсона оценим полуширину квазиуровня как $\Gamma_{m}=\pi \rho_{m} t_{m}^{2}[10-12]$, где плотность состояний металла примем равной $\rho_{m}=N_{m} / W_{m} ; W_{m}$ - ширина зоны проводимости металла, содержащей $N_{m}$ электронов (для $d$-металлов $\left.N_{m}=10\right) ; t_{m}-$ энергия перехода между ближайшими соседями в металле. Поскольку в рамках теории сильной связи $W_{m}=2 z_{m} t_{m}$ (где $z_{m}=12$ - число ближайших соседей в объеме ГЦК-металла [11]), получим $\Gamma_{m}=\pi N_{m} W_{m} / 4 z_{m}^{2}$. Теперь, выбирая конкретный металл, можно с помощью уравнения (1) определить значение $Z_{s 0}$.

Перейдем к определению затравочного (без учета энергетического сдвига $u_{g}$ ) значения заряда атома графена $Z_{g 0}$. Как показано в [6], величина этого заряда равна

$$
Z_{g 0}= \pm \frac{\left(\varepsilon_{\mathrm{D}}-\varepsilon_{\mathrm{F}}\right)^{2}}{\pi \sqrt{3} t_{g}^{2}}
$$

где $t_{g}$ - энергия перехода между ближайшими соседями в графене, верхний (нижний) знак отвечает неравенству $\varepsilon_{\mathrm{D}}>\varepsilon_{\mathrm{F}}\left(\varepsilon_{\mathrm{D}}<\varepsilon_{\mathrm{F}}\right)$. Энергия точки Дирака относительно уровня Ферми равна $\varepsilon_{\mathrm{D}}-\varepsilon_{\mathrm{F}}=\phi_{m}-\phi_{g}$, где $\phi_{g}$ - работа выхода собственного (недопированного) графена. Из (2) следует, что металлическая подложка входит в определение затравочного заряда $Z_{g 0}$ только через уровень Ферми $\varepsilon_{\mathrm{F}}$.

Под влиянием поля металлической подложки заряд атомов графена в первом приближении становится равным

$$
Z_{g}= \pm \frac{\left(\phi_{m}-\phi_{g}-U_{g} Z_{s 0}\right)^{2}}{\pi \sqrt{3} t_{g}^{2}}
$$

Здесь мы положили $u_{g}=-U_{g} Z_{s}$, верхний (нижний) знак в (3) соответствует положительному (отрицательному) значению величины, стоящей в скобках. Отсюда следует, что при

$$
Z_{s 0}^{*}=\left(\phi_{m}-\phi_{g}\right) / U_{g}
$$

имеем $Z_{g}=0$, что отвечает собственному графену. Поскольку $Z_{s}>0$, такой случай возможен, только если $\phi_{m}-\phi_{g}>0$. Тогда при $Z_{s 0}>Z_{s 0}^{*}$ получаем $n$-графен $\left(Z_{g}<0\right)$, при $Z_{s 0}<Z_{s 0}^{*}-p$-графен $\left(Z_{g}>0\right)$.

Исходные данные для расчета и параметры металлических подложек представлены в таблице. Для графена мы положили $\phi_{g}=4.5 \mathrm{eV}$ (как и 
Исходные параметры и результаты расчета (все энергетические величины приведены в $\mathrm{eV}, d_{m}-$ в $\AA$ )

\begin{tabular}{c|c|c|c|c}
\hline \multirow{2}{*}{ Параметр } & \multicolumn{4}{|c}{ Металл } \\
\cline { 2 - 5 } & $\mathrm{Cu}$ & $\mathrm{Ag}$ & $\mathrm{Au}$ & $\mathrm{Pt}$ \\
\hline$W_{m}[13]$ & 2.80 & 3.63 & 5.28 & 7.00 \\
$\Gamma_{m}$ & 0.15 & 0.20 & 0.29 & 0.38 \\
$d_{m}[14]$ & 2.56 & 2.89 & 2.88 & 2.77 \\
$I[15]$ & 7.73 & 7.58 & 9.23 & 8.96 \\
$\phi_{m}(111)[15]$ & 4.98 & 4.74 & 5.31 & 5.7 \\
$\varepsilon_{m}-\varepsilon_{\mathrm{F}}$ & -1.58 & -1.80 & -2.67 & -1.96 \\
$Z_{s 0} \cdot 10$ & 0.15 & 0.18 & 0.20 & 0.26 \\
$\phi_{m}-\phi_{g}$ & 0.48 & 0.24 & 0.81 & 1.20 \\
$U_{g}$ & 5.17 & 4.05 & 4.08 & 4.41 \\
$Z_{s 0}^{*} \cdot 10$ & 0.93 & 0.59 & 1.98 & 2.72 \\
$Z_{g 0} \cdot 10$ & 0.06 & 0.01 & 0.17 & 0.36 \\
$Z_{g} \cdot 10$ & 0.05 & 0.01 & 0.16 & 0.35 \\
$\left|u_{g}\right|$ & 0.15 & 0.14 & 0.14 & 0.27
\end{tabular}

в $[8,9]), t_{g}=2.7 \mathrm{eV}$ и $l=3.35 \AA$, что равно межплоскостному расстоянию в графите. С учетом того, что $S_{m} \sim d_{m}^{2}$, аналогично [6] положим $U_{g} \approx-2 e^{2} A l \exp (-\alpha l) / d_{m}^{2}$, где $\alpha$ - обратная длина затухания поля металлического двойного слоя. Принимая $\alpha=1 \AA^{-1}$, получим значения $U_{g}$, приведенные в таблице. Из (3), (4) и данных таблицы следует, во-первых, что квазисвободный графен на рассмотренных металлах обладает $p$-типом проводимости, что согласуется с результатами $[8,9]$ для $\mathrm{Au}$ и Pt. Отметим также, что учет влияния металлической подложки уменьшает величину заряда атомов углерода графена. Действительно, с учетом малости $Z_{s} 0$ из (3) получим

$$
Z_{g} \approx Z_{g 0}\left(1 \mp \frac{2 U_{g}}{\phi_{m}-\phi_{g}} Z_{s 0}\right) .
$$

Во-вторых, в точке инверсии типа проводимости эпитаксиального графена величина сдвига $\left|u_{g}^{*}\right|$ лежит для рассматриваемых металлов в интервале от 0.2 до $1.2 \mathrm{eV}$, что по порядку величины коррелирует с результатами $[8,9]$. И наконец, малый заряд поверхностных атомов металла $Z_{s}<0.03$ вызывает существенный сдвиг точки Дирака

Письма в ЖТФ, 2018, том 44, вып. 23 
$\left|u_{g}\right| \sim 0.2 \mathrm{eV}$. Этот вывод также качественно подтверждается расчетами $[8,9]$. Отметим, что в настоящей работе и $[8,9]$ использовались не только разные подходы к рассматриваемой задаче, но и разные исходные данные (ср., например, значения $l$ и $\phi_{m}$, приведенные в табл. 1 работ $[8,9]$, с нашими данными). Результаты работ тем не менее качественно совпадают.

Укажем способ проверки предложенной модели. Как следует из выражений (4) и (5), влияние подложки на электронное состояние графена максимально при $\phi_{m}=\phi_{g}$. При $\phi_{g}=4.5 \mathrm{eV}$ (наиболее часто используемое значение) этому условию наилучшим образом отвечают $\mathrm{W}(111)$ и $\mathrm{Mo}(111)$, у которых $\phi_{m}=4.47$ и $4.55 \mathrm{eV}$ соответственно [15]. Здесь, однако, нужно отметить, что разброс значений работ выхода для одной и той же грани одного и того же $d$-металла значителен (см., например, справочник [16]). Следует указать и на различия данных по графену: в [17] приводится значение $\phi_{g}=5.11 \mathrm{eV}$.

\section{Список литературы}

[1] Ristein J., Mammadov S., Seyller Th. // Phys. Rev. Lett. 2012. V. 108. P. 246104.

[2] Давыдов С.Ю. // ФТП. 2012. Т. 46. В. 9. С. 1209-1212.

[3] Mammadov S., Ristein J., Koch R.J., Ostler M., Raidel C., Wanke M., Vasiliauskas R., Yakimova R., Saeyller Th. // 2D Mater. 2014. V. 1. P. 035003.

[4] Slawinska J., Aramberri H., Munoz M.C., Cerda J.I. // Carbon. 2015. V. 93. N 1. P. 88-104.

[5] Slawinska J., Aramberri H., Cerda J.I. arXiv:1501.06486.

[6] Давыдов С.Ю. // ФТП. 2017. Т. 51. В. 5. С. 678-682.

[7] Большов Л.А., Напартович А.П., Наумовеи, А.Г., Федорус А.Г. // УФН. 1977. T. 122. B. 1. C. $125-158$.

[8] Giovannetti G., Khomyakov P.A., Brocks G., Karpan V.M., van den Brink J., Kelly P.J. // Phys. Rev. Lett. 2008. V. 101. P. 02680.

[9] Khomyakov P.A., Giovannetti G., Rusu P.C., Brocks G., van den Brink J., Kelly P.J. // Phys. Rev. B. 2009. V. 79. P. 145425.

[10] Давыдов С.Ю. Теория адсорбции: метод модельных гамильтонианов. СПб.: Изд-во СПбГЭТУ „ЛЭТИ“, 2013. 235 с. Электронный адрес: twirpx.com/file/1596114/

[11] Давыдов С.Ю., Лебедев А.А., Посредник О.В. Элементарное введение в теорию наносистем. СПб.: Лань, 2014. $192 \mathrm{c.}$

[12] Давыдов С.Ю., Трошин С.В. // ФТТ. 2007. Т. 49. В. 8. С. 1508-1513.

Письма в ЖТФ, 2018, том 44, вып. 23 
[13] Ирхин В.Ю., Ирхин Ю.П. Электронная структура, физические свойства и корреляционные эффекты в $d$ - и $f$-металлах и их соединениях. Екатеринбург: УрО РАН, 2004. 472 с.

[14] Киттель Ч. Введение в физику твердого тела. М.: Наука, 1978. 792 с.

[15] Физические величины. Справочник / Под ред. И.С. Григорьева, Е.3. Мейлихова. М.: Энергоатомиздат, 1991. 1232 с.

[16] Фоменко В.С. Эмиссионные свойства материалов. Справочник. Киев: Наук. думка, 1981. $339 \mathrm{c}$.

[17] Mattausch A., Pankratov O. // Phys. Rev. Lett. 2007. V. 99. P. 076802.

Письма в ЖТФ, 2018, том 44, вып. 23 